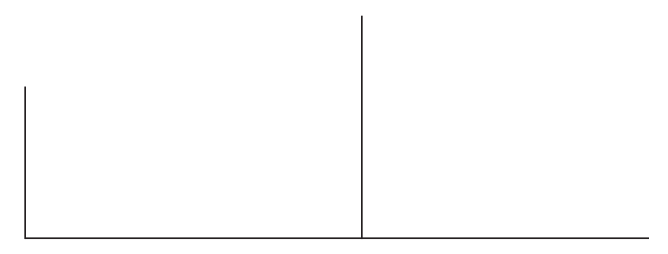

Rev. Latinoam. Psicopat. Fund., II, 3, 124-145

\title{
Notas sobre psicopatologia
}

\author{
Carol Sonenreich \\ Giordano Estevão \\ Luis de Morais Altenfelder Silva Filho
}

\begin{abstract}
O termo Psicopatologia é usado em vários sentidos: equivalente da psiquiatria, da parte da psiquiatria que trata dos distúrbios leves em oposição aos graves, da sintomatologia em oposição à nosologia, teorias do psiquismo e dinâmica emocional. Os assuntos incluídos sob este título são tratados por outros autores como Psiquiatria Geral, Psicologia Médica, Psiquiatria Clínica. Autores dos mais notáveis não definem propriamente o termo, mas indicam quais devem ser os objetivos, os métodos de trabalho que atribuem à Psicopatologia. Escolhemos usar o termo para designar o estudos das teorias sobre o desenvolvimento, funcionamento e alterações das atividades mentais, a interpretação dos sintomas e sinais em função de fatores biológicos e psicológicos, o significado dos distúrbios de relacionamento e conduta, as bases principais dos sintomas de classificação nosológica. Pesquisas e reflexões precisam ser realizadas para atualizar a Psicopatologia. Neste sentido, como exemplo, apresentamos certas propostas para conceituar e trabalhar com os delirantes.
\end{abstract}

Palavras-chave: Psicopatologia, psiquiatria, nosologia, sintoma. 


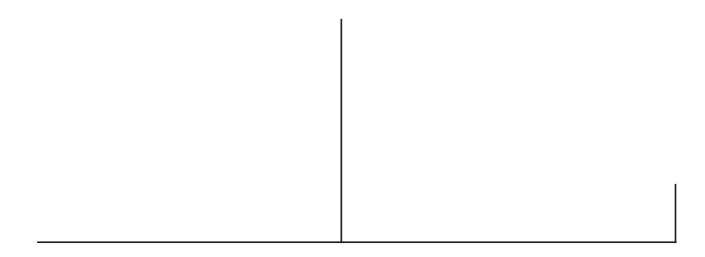

Encaramos a psicopatologia como parte do conhecimento sobre as alterações mentais. Como todo saber, é produto do trabalho dos pesquisadores, dos cientistas que, neste caso, se dedicam ao estudo e tratamento das doenças mentais.

O termo é usado em vários sentidos, o que podemos constatar das definições que lhe são dadas, e ainda mais da observação dos temas, do campo de estudo abordado pelos diferentes autores. Pretendemos aqui trazer considerações a respeito da psicopatologia observando os textos que os autores lhe dedicam.

Andreasen (1997) é categórica: o objetivo de uma psicopatologia científica é identificar os mecanismos neurais dos processos cognitivos normais e compreender como são afetados nas doenças mentais. Ela considera que o projeto de Freud (1895) está sendo lentamente realizado; claro, com postulados novos e recursos tecnológicos atuais. Andreasen entende que os mecanismos neurais podem ser compreendidos como disfunções em circuitos neurais específicos. Suas funções e disfunções podem ser influenciadas ou alteradas por uma variedade de fatores cognitivos e farmacológicos. A proposta é: adotar a posição de que a mente é expressão da atividade cerebral. Os estudos das atividades cerebrais e mentais teriam dois objetivos separados. Mas os fenômenos mentais em si, provêm da atividade cerebral e, por sua vez, as experiências cerebrais afetam o cérebro, de modo que a separação não seria possível. As alterações mentais refletem anormalidades nas interações cérebro/mente, e nas relações do indivíduo com o mundo. São doenças da mente, que reside naquela região do soma que é o cérebro. O método básico de estudo é dividir a mente em componentes, domínios de investigação (memória, linguagem, atenção etc.) relacioná-los com lesões cerebrais localizadas, com o desenvolvimento neural, aprender com pesquisas homólogas feitas com animais. O desafio da psicopatologia científica é o de usar disciplinas múltiplas. 




Não pretendemos aqui analisar as propostas de Andreasen. Apenas queremos apresentar o que ela chama de psicopatologia. Somente vamos mencionar que a autora, de fato, não define o termo, mas diz como deveria ser estudado. E, pelas tarefas multidisciplinares que lhe atribui, sugere que psicopatologia designa a mesma coisa que psiquiatria.

Kandel (1998), no artigo "New intellectual framework for psychiatry", referese em grande parte aos mesmos problemas, sem recorrer ao termo psicopatologia. A maior parte do artigo é dedicado à tecnologia dos estudos que pretendem associar mente e cérebro, no que seria a psicopatologia científica.

Brockington e Howard escrevem, em 1997, "Cem anos de psicopatologia". Segundo eles, o sentido do termo mudou radicalmente durante um século de uso. Rigorosamente falando, significaria morbidade da mente, mas, na linguagem contemporânea, refere-se seja à dinâmica emocional, seja à descrição dos sintomas psíquicos. A nosologia procura reduzir a complexidade isolando categorias de doenças, colocando ordem e conexões entre fenômenos, criando entidades cuja unidade é procurada na etiologia e genética. A psicopatologia considera que os sintomas em si são dignos de estudo, e examina suas relações com as estruturas e funções do cérebro. Os avanços em radiologia, ressonância magnética, tomografia com emissão de positrons, gravações auditivas do discurso sub-vocal concomitante, constituem a metodologia na qual se baseia o estudo atual da psicopatologia, junto com a investigação neuroquímica do líquido céfalo-raquidiano, os testes endocrinológicos, do eixo pituitário-adrenal, dos neurotransmissores e receptores sinápticos.

Para ilustrar suas afirmações, os autores escolhem as pesquisas psicopatológicas no campo das alucinações, delírio, transtornos do humor. Dizem: apesar dos tremendos progressos obtidos com tais abordagens, temos que admitir que os resultados dos estudos não foram consistentes, e levantaram mais questões do que resolveram sobre a gênese das alucinações. As alucinações correspondem a atividades corticais que não podem ser diferenciadas das atividades dos sujeitos normais. O monitoramento do discurso interior, estudado por tomografias com liberação de um único foton, não identifica diferenças entre a fase alucinatória dos esquizofrênicos e uma fase ulterior - 19 semanas mais tarde -, sem alucinações. A ressonância magnética mostra alterações em esquizofrênicos com alucinações auditivas graves; mas também elas persistem quando os mesmos melhoram. Embora não tenham sido identificadas anormalidades funcionais ou de estrutura cerebral que possam fazer o diagnóstico de esquizofrenia, devido a aplicação da neuroimagem, a maioria dos psiquiatras aceitaria que modificações cerebrais acompanham as alterações psíquicas.

Evidentemente, os sentidos dados ao termo psicopatologia são múltiplos. Não mudaram somente ao longo do tempo, mas, mesmo sincronicamente, vários 




significados lhe são dados. Muitas vezes o autor sequer define o que pretende dizer com esse termo. Aqui, Brockington e Howard mostram sua escolha: a descrição dos sintomas e seu estudo com recursos tecnológicos de registro do funcionamento cerebral. Admitem que outros entendem por psicopatologia o estudo da dinâmica emocional.

A nosografia seria o capítulo do saber psiquiátrico que elabora categorias, unidades classificáveis, organizadas (segundo Brockington e Howard) pela etiologia e genética. Devemos entender que eles excluem do programa de pesquisa psicopatológica a etiologia e a genética? A valorização do sintoma, em si, como objeto de estudo, é coerente com o espírito das classificações contemporâneas, CID10 e DSM-IV, que preconizam uma abordagem diagnóstica ateórica, baseada em descrição de sintomas. O estudo isolado dos sintomas ou de categorias de manifestações é muitas vezes considerado psicopatologia. No capítulo "Esquizofrenia" o item psicopatologia expõe a sintomatologia desta doença, no Clinical Psychiatry de Mayer-Gross (1954). Em Talbott (1988), o título Psicopatologia é dado ao parágrafo que descreve os sintomas provocados por Cannabis (p. 20), Diabetes mellitus (387), Retardamento mental (519).

Cervera-Enguix (1993) escreve sobre as manifestações psicopatológicas fundamentais da anorexia nervosa: Quais são estas manifestações? Quais são os principais sintomas psíquicos? Quais são os sintomas secundários? (p. 324). Obviamente encara a manifestação psicopatológica como sintoma.

Autores que optam pelo método clínico-descritivo, e lhe atribuem grandes avanços, usam também a psicopatologia experimental, como extensão do método clínico (Gelder, 1993). Sob o título Psicopatologia, apresenta-se a sintomatologia submetida a estudos. A psicopatologia de Jaspers era caracterizada pelo método fenomenológico. A que Brockington analisa é caracterizada pelos métodos de pesquisa oferecidos pela tecnologia do nosso tempo.

Formular elementos quanto mais simples para estudá-los em relação ao funcionamento cerebral, corresponde às propostas cognitivistas de trabalhar com fenômenos psíquicos elementares, com modelos, módulos. As tentativas de esclarecer processos mais complexos, delírios, alucinações, distúrbios do humor, são, segundo estes autores, comprometidas pela complexidade dos objetos de estudo. Não concordamos com os conceitos de delírio, de alucinação que usavam. $\mathrm{O}$ fato é que eles devem admitir: as pesquisas dizem muito sobre o funcionamento do cérebro, e nada concludente sobre os processos mentais. A própria metodologia cognitivista adota a idéia de usar sistemas diferentes de conhecimento para vários níveis de problemas. De usar níveis diferentes de abordagem. A psicopatologia precisa determinar que níveis de atividades quer estudar e adequar-se a seus próprios propósitos. 

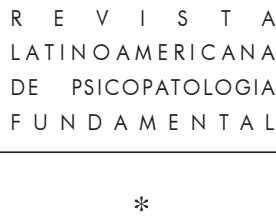

* *

Para Falret (1864), a anatomia cerebral não explicava os fenômenos psicológicos. A tecnologia contemporânea, aplicada ao estudo do cérebro, será que vai explicar?

Física, química, biologia têm níveis específicos de aplicação. Não podemos esperar que a associação entre elas resolva as questões da cibernética, ou da medicina, ou da psicopatologia.

Ribot (1881) usava o termo Psicologia Patológica para descrever os distúrbios das manifestações psicológicas. Analisava as funções psicológicas normais e patológicas, em termos de excessos e deficiências. Não entrava em nosologia e terapia. Em 1905, Dumas dava um curso com este nome.

O termo psicopatologia é freqüentemente usado como equivalente da Psiquiatria (estudo e tratamento dos distúrbios mentais). Seria um termo dos mais imprecisos, um eufemismo para não falar de psiquiatria (Lebovici, 1990). Lemos a definição: Ciência dos sofrimentos do espírito, ramo da psicologia e reflexão teórica sobre a clínica psiquiátrica (Postel, 1998). O estudo dos distúrbios mentais como patologia e fisiologia ... A psicopatologia quantitativa dedica-se a medir de modo sistemático os distúrbios psíquicos (Thuillier, 1996, pp. 689 e 691). Estudo sistemático da etiologia, sintomatologia e processos dos distúrbios mentais. E aquela parte da psicologia anormal que se ocupa com doenças, enfermidades e defeitos de adaptação (Arnold, 1976). Ramo da ciência que trata da morbidade ou patologia da psyché ou mente (Hinsie, Campbell, 1960). Ramo da psicologia médica consagrado ao estudo e funcionamento anormal do espírito humano (Sillamy, 1980). Psicopatologia é a patologia das doenças mentais (Blakinston, New Gould Dictionary, 1956).

Monedero (1973) no livro Psicopatologia geral apresenta dois capítulos: semiologia, nosografia. Não quer uma enumeração estéril de sintomas, mas uma visão panorâmica das manifestações patológicas do psiquismo, uma ciência do psiquismo doente.

É freqüente encontrar os itens tratados como psicopatologia separados daqueles tratados como da Psiquiatria Clínica, sendo esta última igual à nosografia (VallejoNagera, 1970; Nobre de Melo, 1970). Outras designações como Psiquiatria Geral, Psiquiatria Clínica, Psiquiatria Médica, Psicologia Clínica, tratam os problemas (funções psíquicas, instintos, temperamento, personalidade, evolução etc.) incluídos por outros na psicopatologia.

O vasto Handbook of Psychiatry editado por Shepherd e Zangwil (1983), tem um primeiro volume de Psicopatologia Geral, expondo as bases históricas da psiquiatria, o estudo geral dos distúrbios (memória, emoção, linguagem), os 


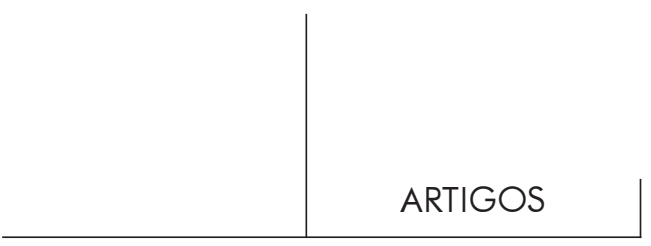

princípios taxonômicos e terapêuticos. Nos outros 4 volumes os quadros nosológicos, como unidades, são estudados sob todos os aspectos.

Os distúrbios leves podem ser o território da psicopatologia, enquanto os graves pertenceriam à psiquiatria. Outros atribuem à psicopatologia as alterações quantitativas, deixando para a psiquiatria os distúrbios qualitativos.

A descrição dos sintomas (semiologia) não basta para qualificar, para certos autores, a psicopatologia. Esta seria o ramo do saber que formula teorias sobre os distúrbios mentais. As Teorias da Psicopatologia (biofísicas, intrapsíquicas, fenomenologias, comportamentais) seriam a substância da psicopatologia (Millon, 1969). A psicopatologia estudaria as teorias do conhecimento, e seus fenômenos especiais (Deshaies, 1967).

As teorias podem proporcionar uma compreensão mais profunda sobre os mecanismos psicoterapêuticos, o funcionamento da mente na normalidade e na psicopatologia (Marmer, 1988).

Contra o ateorismo que leva a uma semiologia e clínica que pretendem chegar à universalidade pelo método de pesquisa de opinião, que suprime o pluralismo e o debate de idéias, substituídas pelo perfeccionismo descritivo e mecânico, Angelergues (1990) defende a psicopatologia: lugar de incerteza onde se afrontam as influências teóricas.

Del Pino (1993) prefere escrever Psico(pato)logia destacando as ligações com a psicologia. Seria a fundamentação teórica da psiquiatria. Qualquer pesquisa epidemiológica, genética, metabólica, histológica, química, psicossocial, psicodinâmica, nosológica etc., deve começar com a psiquiatria clínica. Esta comporta problemas gerais (teoria e epistemologia psiquiátricas) e psicopatologia.

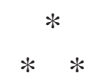

Não conhecemos autores que ao falar de psicopatologia deixem de citar Jaspers (1913). Até para evocá-lo apenas, sem assumir nenhuma das suas idéias. Jaspers queria formular uma ciência para conhecer e reconhecer, caracterizar o homem. Conceitos com significações constantes, comunicáveis, seriam elaborados para conhecer o fenômeno psíquico patológico, as enfermidades psicológicas ou psiquicamente determinadas. Neurologia, Medicina Interna, Fisiologia, seriam ciências auxiliares importantes. Mas a medicina da mente, a psiquiatria, é uma prática, implicando também intuições, impressões incomunicáveis; seria, portanto, também arte, habilidade, não puramente ciência. A psicopatologia sim, seria ciência, que deve nos fornecer uma compreensão descritiva, fenomenológica, das formas anormais de experiência e conduta. Jaspers determinava o método de trabalho da psicopatologia: o fenomenológico. Os achados físicos que têm, ou podem ter, certa 


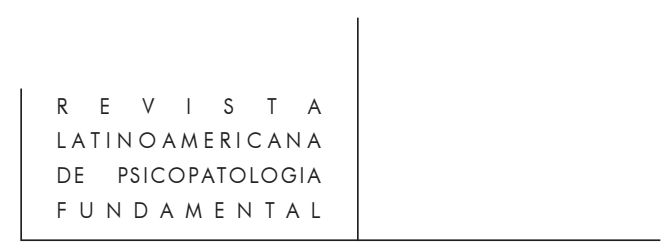

relação com os eventos psiquiátricos, não os retratam nem os revelam em nenhum sentido que possamos compreender.

Minkowsky (1966) também concebe a psicopatologia como um modo de abordar as funções perturbadas. Procura compreender os distúrbios subjacentes, ligados à personalidade inteira, atingida em sua estrutura e seu modo de existir (p. 13). Não se trata de descrever os sintomas sem analisar sua significação. Só descrevendo alterações de memória, percepção, consciência, não indicamos significado algum da respectiva alteração, que só tomaria sentido dentro de uma estrutura. A descrição não mereceria o nome de sintoma. E as síndromes psiquiátricas não são apenas um grupo de sintomas que coexistem com regularidade e revelam assim sua origem comum. (p. 49)

Para Binswanger (1922), o expressivo nunca é fenômeno isolado. As teorias devem explicar os fenômenos, em função da vivência. A tarefa seria encaixar as manifestações numa visão geral, atribuir-lhes significados. A psiquiatria clínica, ramo da medicina, encarrega-se do diagnóstico e tratamento. A psicopatologia é reflexão e filosofia estudando o fato clínico na existência humana. As manifestações melancólicas, por exemplo, devem ser analisadas em função do modo de estar no mundo, vivência do tempo, do espaço.

A psicopatologia, como corpo de saber, é ainda necessária? perguntam Huber e Gross (1993). Eles defendem seu uso e apresentam especificamente a psicopatologia fenomenológica como a disciplina que, com a ajuda da introspecção do paciente, e a empatia e compreensão genética do investigador, intenciona entender o movimento, as conexões e a continuidade da vida psíquica com distúrbios neuróticos e psicóticos. A fenomenologia e a compreensão genética tornam o psiquiatra (sic!) ao mesmo tempo um médico participante e um que se coloca à distância, que observa e registra sinais e sintomas, e também usa a si mesmo como instrumento de exploração. A habilidade de atenuar distância entre uma atitude centrada na personalidade e outra centrada no diagnóstico, é o critério essencial. Assim, Huber e Gross encaram a abordagem do paciente e o discurso da psicopatologia.

Os autores que falam de psicopatologia, situando-se dentro do pensamento neurobiologista, não contestam a necessidade da psicopatologia, mas a definem e caracterizam conforme suas posições principais.

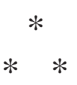

Jaspers ainda inspira psicopatologistas que aplicam suas idéias, ou as tomam como ponto de partida para novas elaborações. Vejamos por exemplo Kimura Bin (1993) que fala da psicopatologia fenomenológica - uma reflexão sobre consciência, estar no mundo - e que estudando o fenômeno patológico nas manifestações e 




consciência do paciente, pode constituir uma ciência autônoma. Um diagnóstico fenomenológico intuitivo é possível. Teríamos que tomar em consideração o aïda, o auto-encontro, a particularidade do homem, a essência do ser; também o ningen (homem-entre). A relação entre estas duas instâncias conceituais faz com que o autor qualifique (nomeie) a sua psicopatologia de interpessoal. Esta noção nos sugere a transcendência, característica humana na visão fenomenológica, existencialista. Kimura prefere os conceitos ä̈da e nin-gen, e estuda os quadros esquizofrênicos como patologia do ä̈da.

Citamos este autor porque ele se apresenta como um continuador de Jaspers, com familiaridade com Binswanger, Gebsattel, Tellenbach, Boss. E porque o encontramos entre os trabalhos publicados por uma revista de Psicopatologia Fundamental, portanto, é identificado com os objetivos desta revista (contribuir para o desenvolvimento da Psicopatologia Fundamental).

A Psicopatologia Fundamental propõe tarefas no campo da 1) delimitação teórica entre as diversas disciplinas envolvidas no campo de psicopatologia; 2) teorização do papel dos modelos e paradigmas no campo da psicopatologia; 3) resgatar a dimensão subjetiva no estudo dos sofrimentos psíquicos (Pereira, 1996). Pretende situar-se como uma nova disciplina, dialogando com a abordagem empírica das classificações oficiais atuais. Não pode começar sem situar-se diante da psicopatologia, que Jaspers considerava base teórica da psiquiatria, do estudo das vivências como dado imediato da consciência. Mas a generalização, implicada pela ciência que Jaspers elabora, é possível quando se aspira atingir a singularidade da experiência do sofrimento individual. A fenomenologia não poderia tratar o homem como objeto de conhecimento, independente do observador; não poderia proceder como as ciências da natureza empírico-experimentais. Se a fenomenologia se limita ao que pode ser vivido e apreendido no plano da consciência, ela acantona-se como a Geometria, as essências puras. Descrever o tipo psicológico das diversas formas de sofrimento psíquico, produziria modelos protótipos próprios a cada quadro clínico.

A Psicopatologia Fundamental seria indissociável de um debate com a história da psicopatologia. A psicanálise traria a dimensão da subjetividade no centro da psicopatologia. Tal dimensão precisa ser considerada na abordagem do sofrimento humano, como também o resgate da paixão e do sofrimento, com sua capacidade geradora de sabedoria, a subjetividade.

A tais problemas, a tais limitações ou dificuldades encontradas na fenomenologia jaspersiana, Fédida responde propondo a Psicopatologia Fundamental, para cuja elaboração e desenvolvimento, vários autores brasileiros e estrangeiros trabalham.

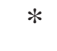




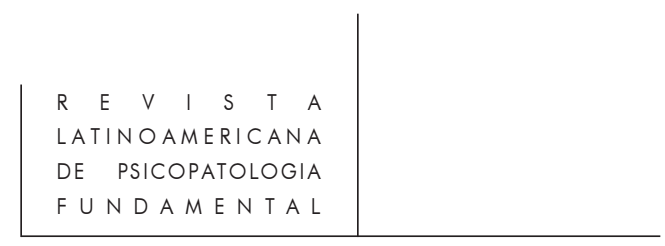

As neurociências, a psiquiatria biológica qualificada como "ortodoxia" da psiquiatria atual, não liquidaram, nem tentaram liquidar, o pensamento psicanalítico. Ninguém proíbe as atividades psicanalíticas, nem as expulsa dos debates acadêmicos do ensino, das pesquisas. Duvidamos que para manter a psicanálise viva seja necessário usar verdades parciais, ou invenções completas, contra o "perseguidor" neurocientista.

Afirmar que a biologia é o fundamento incontestável da psicopatologia na atualidade é correto, para certa parte dos psicopatologistas. Assim como é verdade que a psiquiatria foi predominantemente psicanalítica nos anos 40-60, somente se nos referirmos a uma parte dos psiquiatras, especialmente americanos. Não seria possível ignorar a influência do psicobiologismo de Adolf Meyer, ou do comportamentalismo skinneriano na psiquiatria e psicopatologia americana. O considerável American Handbook of Psychiatry de Silvano Arieti (1959), na sua 11ª edição (em 1972), dedica, do total de 2098 páginas, 85 à psicanálise, 81 às outras psicoterapias, 100 a terapias físicas. As teorias freudianas são expostas em meia página, no capítulo "Teorias da personalidade" (pp. 88-113), ao lado das teorias comportamentais, gestaltistas.

É impossível atribuir à psicanálise um papel predominante naquela época, se tomarmos em consideração os trabalhos de Aubrey Lewis. Nem o tratado de MayerGross e col. (1954) que, no capítulo "Escolas contemporâneas" (pp. 10-40) dedica 4 páginas a Kraepelin, 5 à psicanálise, 5 a Pavlov, 2 à análise existencial, 1 à psicobiologia, a multidimensionais.

Na França não é de estranhar o papel muito discreto atribuído à psicanálise, por Henry Ey, criador do organo-dinamismo, tanto no seu manual (1963), quanto na Enciclopédia Médico-Cirúrgica da qual é o editor . Outras figuras proeminentes da época, J. Delay, H. Baruk não são mais próximos da psicanálise do que Ey. Entre os autores de língua alemã, Eugen Bleuler tinha falecido em 1939, e L. Binswanger desde os anos 40, criava a análise existencial. Aliás, na Alemanha dos anos 30 e na URSS dos anos 50, a psicanálise era proibida.

Dizer que nos anos 70 a psiquiatria renegou suas bases psicanalíticas e descobriu nas neurociências, fundamentos para proclamar sua vocação médica, para construirse uma nova identidade nos parece demais superficial. Não podemos esquecer que a medicina, desde Hipócrates, assume propostas com respeito aos distúrbios psíquicos. A psiquiatria, já com este nome, tentou fazer da Paralisia Geral Progressiva (Bayle, 1822) seu padrão de pensamento. Griesinger elaborava na base de patologia cerebral, seu Tratado das Doenças Mentais (1845).

Entre os psiquiatras contemporâneos ganharam amplo espaço sistemas de psicoterapia que se afastam da psicanálise. Mas as propostas "dinâmicas", e psicanalítica como tal, estão presentes nos livros e artigos psiquiátricos nas instituições psiquiátricas. 


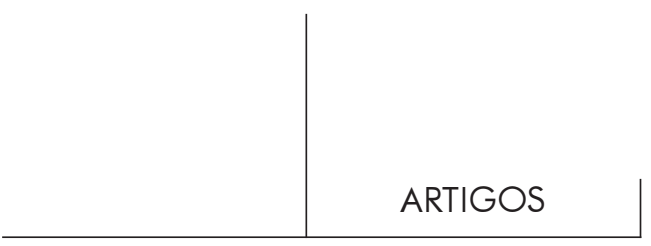

Os Practice Guideline para as mais importantes patologias mentais, publicadas pela American Psychiatric Association, contêm recomendações de psicoterapias, incluindo psicodinâmicas psicanalítica. Não são predominantes, talvez porque os psicanalistas não achem interessante debater resultados, procedimentos, com outros métodos psicoterapêuticos.

Quem proclama que os psiquiatras condenam e recusam qualquer aproximação com a psicanálise, ficaria muito surpreso com a leitura de Kandel (1999), autor do considerável tratado Principals of Neural Science (1985). Ele acha lamentável que a psicanálise, tão criativa na obra de Freud e seus seguidores, na primeira metade do século, a ponto de revolucionar nossa compreensão da vida mental, deixou de ter realizações impressionantes na segunda metade (fora, talvez, de certos progressos na questão do desenvolvimento infantil). Não elaborou métodos de verificação, não evoluiu cientificamente. Porém, ainda seria a mais coerente e intelectualmente satisfatória visão da mente. A proposta que Kandel faz aos psicanalistas é: desenvolver as ligações com a biologia em geral, e as neurociências em particular. Caminho que, por enquanto, seria seguido só excepcionalmente pelos psicanalistas. $\mathrm{Na}$ questão do inconsciente do determinismo intra-psíquico, as pesquisas no campo das neurociências ofereceriam consideráveis esclarecimentos, com aplicação procedural, na psicoterapia. Um diálogo genuíno entre biologia e psicanálise é necessário, se queremos completar uma compreensão coerente da mente, escreve Kandel, o mesmo psiquiatra biologista que foi ouvido nas sessões plenárias das reuniões anuais do Colégio Americano de Neuropsicofarmacologia (1994), que propõe um novo quadro intelectual para psiquiatria publicado no American Journal of Psychiatry em 1998 (155: 457-469).

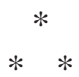

Um argumento usado para desmascarar uma espécie de fobia de psicanálise entre os psiquiatras, seria que esta se concentraria ultimamente em três patologias: depressão, toxicomanias e síndrome de pânico. Tal interesse, injustificado, corresponderia ao discurso centrado em acontecimentos corporais.

Em primeiro lugar, sem recorrer a uma autêntica pesquisa da literatura, mas apenas observando os últimos números de várias publicações - Revista ABP (1999; 21: 1), Jornal Brasileiro de Psiquiatria (1999;1: 2-3), American Journal of Psychiatry (1999; 156: 4), Archives of General Psychiatry (dez; 1998; 55 (12) 1,2,3,4), British Journal of Psychiatry (1999; jan-fev-mar), Acta Medica Scandinavica (1998; nov. 5) - tal afirmação é inexata. Encontramos um só artigo dedicado à Síndrome de pânico, vários sobre Transtornos fóbico-obsessivos, e os artigos sobre depressão, toxicomanias não são, em caso algum, mais numerosos 


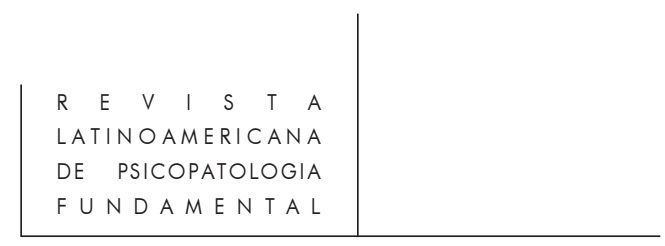

do que os sobre esquizofrenia, Alzheimer, transtornos de personalidade. Sem falar de trabalhos sobre medicação, psicoterapias, diagnóstico clínico e de laboratório.

Seria absurdo estranhar a predominância de estudos sobre drogas em publicações como o J of Substance Abuse, ou J of Addiction Disorders, ou homólogas para Distúrbios Afetivos

Não há nenhum mistério no interesse pelas toxicomanias. A presença dessas na clínica é cada vez mais marcante. A associação do uso de drogas com violência, acidentes, prejuízos econômicos, faz com que o tema esteja na pauta da sociologia, antropologia, política, economia, pedagogia. De fato, a intervenção psiquiátrica e psicológica é cada vez mais limitada, o que achamos mais do que legítimo. A psicanálise, na primeira metade do século, interessava-se muito pelo assunto e elaborou teorias psicogenéticas interessantes. Não teve, porém, bastante interesse pela terapêutica e agora parece ter ainda menos. Para intervenções na família dos drogados, na comunidade, nas empresas, nas escolas, tão valorizadas atualmente, as psicoterapias não-analíticas são incomparavelmente mais presentes, mais atuantes. O papel da psiquiatria é naturalmente cada vez mais limitado. O da psicanálise, que ela mesma deveria definir, nos parece quase nulo.

A depressão é um tema de primeira linha. Os casos assim diagnosticados, conforme os critérios das classificações oficiais, são cada vez mais numerosos. A produção de remédios desde 1953 em contínua atuação, favorece, sem dúvida, os estudos e o campo de trabalho médico. Como acontece também com os ansiolíticos, a maior prescrição de antidepressivos nem é feita pelos psiquiatras, mas por outros médicos, o que influencia a visão desta patologia por parte do público consumidor e da medicina. Mas também para a depressão foi inicialmente proposta a psicoterapia cognitiva, que depois aplicou-se a outras doenças. Atualmente são indicadas intervenções psicoterapêuticas para praticamente todos os diagnósticos. Formas de intervenção são recomendadas no que, conforme certos códigos, seriam psicoses, neuroses, psicopatias, distúrbios orgânicos. Se a psicanálise não é mais a preferência dos terapeutas, médicos e não-médicos, ela não deixa de representar uma parcela enorme das despesas feitas com o tratamento da depressão nos EUA. Em 1990, dos 19 bilhões de dólares gastos com tratamento das depressões, as psicoterapias individuais consumiram mais de 50\% do total ( $\mathrm{Hu}, 1995)$.

O considerável crescimento dos distúrbios mentais ligados à velhice, abre campo para amplos estudos e intervenções psiquiátricas. É inegável a profunda e freqüente associação entre tais distúrbios e a depressão, o que constitui mais uma razão (nada misteriosa), para pesquisar o que pode constituir o capítulo depressão.

O conceito em si, tratado ultimamente como "transtorno afetivo", ainda provoca debates, nos quais, aliás, participamos. Não o consideramos fértil e tentamos pensá-lo de uma maneira mais adequada para pesquisa e tratamento (Sonenreich et al. 1991). Achamos que embora agindo dentro do campo da 




psiquiatria biológica, objetamos contra os métodos e idéias reducionistas, e tentamos desenvolver uma psicopatologia livre do dualismo, dos preconceitos. A psicanálise freudiana não é nossa opção, como não é nem o diagnóstico por soma de sintomas (Sonenreich, 1990) nem a igualização do saber psicopatológico com o neurofisiológico.

A “Síndrome do pânico” introduzida na classificação psiquiátrica com o DSMIII (1980), despertou muitos entusiasmos, muitos estudos. Debates, também. É um erro confundir esta entidade com as fobias. Fazem parte da categoria transtornos ansiosos, mas não são termos idênticos. Podem associar-se manifestações fóbicas com crises de pânico, e tal associação achou várias interpretações, vários significados, mas não são noções que podem ser equiparadas. Fobias, obsessões, compulsões constituem outros itens da classificação. O tratamento inclui remédios, mas antes deles - em geral - são citados as intervenções comportamentais, cognitivocomportamentais, psicodinâmicas (Gabbard, 1995).

Qualquer que seja o grau no qual aceitamos, usamos na clínica e na pesquisa, o conceito de transtorno de pânico, não podemos considerá-lo como uma invenção dos psiquiatras para livrar-se da sombra da psicanálise.

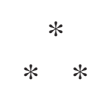

Consideramos básicas as questões como a relação entre a generalidade de uma ciência (seja ela a Psicopatologia, como a quer Jaspers) e o caráter individual, único de cada pessoa.

Nossa tentativa de resposta situa-se no plano dos conceitos de ciência e de pessoa (em sofrimento ou não). Achamos necessário separar nitidamente o conceito de ciência (um discurso sobre qualquer objeto), do conceito de pessoa sofrendo (neste caso, objeto da ciência do discurso). A pessoa, com seus sofrimentos, é abordada por vários modos de conhecimento (filosófico, mítico, religioso, ético etc). Conforme seus pontos de vista, o mago, o feiticeiro, o sacerdote, o curandeiro, encaram e tratam os sofrimentos físicos e psíquicos. A medicina tem as suas propostas, consideradas científicas ou não, segundo a definição que o respectivo autor da à ciência. Jaspers, por exemplo, não considerava que a psiquiatria, a versão médica sobre os distúrbios mentais, correspondia aos critérios da cientificidade. Outros rejeitam a psiquiatria justamente por ser científica, ou ter a pretensão de agir num espaço no qual as ciências não teriam o que dizer. Estes últimos críticos deixam em geral de especificar como definem o caráter científico de uma disciplina.

Nossa opção é definir como científico o tipo de conhecimento que estuda seus objetos em função de um quadro de referência. Seja ele numérico, seja um esquema teórico (como o triângulo edipiano, por exemplo). A ciência deve ser criticável, 


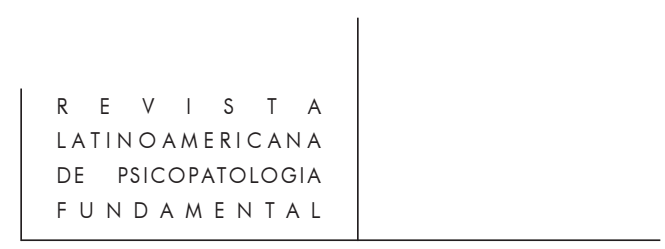

portanto passível de ser comunicada aos outros cientistas. Implica coerência interna e aplicabilidade às questões teóricas e práticas que pretende tratar. Assim vista, a ciência não pode ser pensada como puramente pessoal, como seria uma revelação divina, uma inspiração. Precisa ser compartilhada, portanto, formulada em termos que a coletividade científica possa entender, em conceitos, cujo significado precisa ser entendido pelos outros, em teorias que os outros possam compartilhar ou rejeitar. A ciência é influenciada pela cultura do tempo e não pode ser o saber de um só iniciado. Ela pode ser aplicada ao uso individual; à pessoa, que consideramos única, irreprodutível (pelo menos até que os clones venham colocar a questão em outros termos). Não podemos imaginar uma ciência que diz tudo sobre a pessoa, sobre toda a pessoa. A ciência é um modo de abordar aspectos da pessoa, de tratá-los.

Falamos da doença como um conceito, ponto de vista médico. A pessoa é abordada deste ponto de vista. Formulamos doenças, como instrumento para nossas atividades médicas. Às vezes passamos a falar delas, como se fossem realidade em si já que, independentemente da existência do médico, é o paciente que as sofre. São situações vividas pelo paciente, mas concebidas como doenças pela medicina.

Os números foram inventados para resolver problemas humanos. Chegaram a ser considerados, por certos filósofos, como tendo essência própria que os humanos procuram decifrar. Achamos indiscutível que para nós todos, que trabalhamos sempre com números, o que interessa é seu caráter de instrumento que nos serve na vida.

O metro é uma unidade inventada por nós, com aplicabilidade universal para as dimensões que mede. Não pretende dizer tudo sobre a pessoa medida. Mas não conhecemos nenhuma maneira de abordagem que fale tudo sobre o ser estudado.

Entre discurso e seu objeto deve, sem dúvida, existir uma correspondência. Mas não identidade. As características do objeto estudado não são as mesmas que as características do discurso.

Doença vista como instrumento de ação médica, é um construto de ordem geral, útil ,na verdade, somente dentro da medicina. Neste sentido achamos pertinente usar uma Psicopatologia geral, para entender problemas e situações de uma pessoa única. Formular em termos psicopatológicos, é para nós instrumental da atividade com a pessoa e sua história.

A subjetividade não é excluída dos procedimentos da ciência. Existem cientistas que não querem abordar a questão e atribuem a seus estudos outros objetivos (Minsky, 1988). Mas os físicos postulam: não há observação sem a participação do observador. Invocar sempre a eliminação do subjetivo nas ciências, é negar os físicos e matemáticos que teorizam a presença do subjetivo, do estético, das suas pesquisas. Físicos que foram laureados com Prêmios Nobel.

O estudioso que examina e trata o paciente não fala pelo paciente. Ele descreve, analisa, interpreta o que ele mesmo colheu do exame. Observa e qualifica em função 


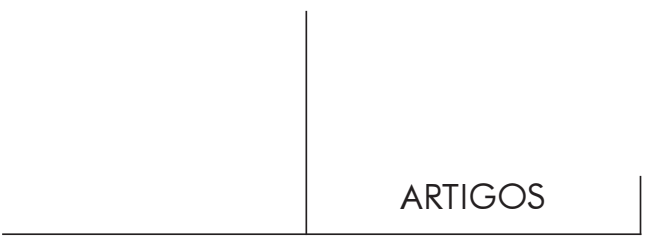

de seus conhecimentos, das doutrinas que o orientam, do saber que adquiriu por estudos e experiências.

Não consideramos que a psicopatologia, como ciência, exclui por definição o subjetivo, ou que este seja, por definição, apanágio de um certo autor ou sistema psiquiátrico, psicopatológico, psicanalítico.

A psicanálise freudiana, assim como a existencial, são as vezes incluídas no capítulos "interpessoais". Postulam-se como encontros entre dois interlocutores, assim como salientam a participação subjetiva. As duas podem ser entendidas como sistemas de pensamento universalmente aceitáveis, embora aplicados a casos individuais. A construção teórica destes tipos de conhecimento não nos parece essencialmente oposta a outras ciências. Não diríamos que a contribuição de Freud na constituição da nosologia psiquiátrica foi seu maior mérito. Ele propôs interpretações diferentes, psicodinâmicas, em função dos seus quadros referenciais teóricos, para entidades nosológicas já construídas por outros autores, já classificadas por Kraepelin. A esquizofrenia (assumida por Kraepelin), a psicose maníaco-depressiva, a histeria, os quadros fóbicos, os obsessivos, o delírio, eram termos já consagrados. Freud os usou, propondo interpretações diferentes, às vezes polemizando com autores que entendiam fobias, obsessões, ansiedade de outras maneiras, em outros agrupamentos, outras interpretações. O grande êxito da psicanálise na psiquiatria americana (predominantemente) identifica-se na interpretação e tratamento dos distúrbios, não na nomenclatura ou classificação.

A direção tomada pela psiquiatria oficial das grandes organizações americana e mundial, lançou-se com declarações de oposição contra a psicanálise e o comportamentismo. $\mathrm{O}$ ateorismo proclamado inicialmente é quase negado hoje, já que se usa tanto a expressão neurociências cognitivas, ou psicoterapia cognitivocomportamental. O que achamos mais característico é a consagração das avaliações quantitativas, a procura de validação empírica, a predominância das pesquisas básicas deixando as clínicas mais para o tratamento estatístico.

Isto exclui a Psicopatologia? Não nos parece óbvio. Claro que sugere a opção para certa definição da Psicopatologia. Por exemplo, como trabalho psicopatológico no passado, Brockington e Howard (1973) citam o reconhecimento de entidades diagnósticas. Os grandes fatos psicopatológicos teriam sido descrever e dar nomes específicos a certos quadros, como fizeram Ganser, Kretschmer (com o delírio sensitivo de referência), Aspergen (com o autismo infantil), Ascher (com a Síndrome de Munchausen), Russel (com a bulimia nervosa). E para o próximo século, esperam descrições de novos fenômenos psicopatológicos, cujos pormenores e localização (sic!) serão esclarecidos pelas novas técnicas de exploração.

Entendemos por Psicopatologia não somente a descrição de sintomas ou formulação de novos quadros diagnósticos, mas o estudo das alterações, das relações entre elas, do seu significado para a existência do paciente, das teorias que nos 
permitam formular nosso entendimento científico e nossas condutas diante da doença mental.

$* \quad *$

As publicações contemporâneas que colocam nos seus títulos o termo Psicopatologia, abrigam estudos dos mais variados tipos.

Entre os 73 títulos que nos foram fornecidos pelo computador, publicados na revista Psychopathology (Basel-Karger) encontramos: estudos de sintomas, descrições e relações com alterações cerebrais ou doenças físicas ou psíquicas (19); conceitos, significados, vulnerabilidade, estágio de defesa (16); epidemiologia e etiologia (10); marcadores e medidores químicos, biológicos (8); nosologia, discutindo e contestando entidades classificadas em CID-10 e DSM-IV (7); fatores culturais (5); apresentações de casos (5); terapia, hospitalização (3).

Os respectivos trabalhos foram realizados na Alemanha (16), Itália (8), Japão (7), Inglaterra (6), França (4), Suécia e Israel (4), Áustria, Suíça, Grécia, EUA (3), Irlanda (2), Brasil, Argentina, Chile, Croácia, Dinamarca, Espanha, Hungria, Polônia, Turquia, Iugoslávia.

Temas variados, autores de países diversos, mas não podemos estabelecer nenhuma relação significativa entre as questões estudadas e o país.

O Journal of Psychopathology and Behavior Assessment (EUA) publicou entre 17 artigos que lemos, 16 de pesquisas realizadas nos EUA, 1 na Holanda, portanto é evidentemente mais centralizado. Os trabalhos falam de instrumentos de pesquisa, entrevistas, escalas (8); conceito de depressão (3); significado psicodinâmico das fobias (2); comorbidade (2), psiquiatria forense (1).

Também uma informação obtida pelo computador, nos periódicos cujo título contém a palavra Psicopatologia, os artigos são classificados em: 1) psicopatologia, 2) psiquiatria da família; 3) identificação e propostas psiquiátricas na educação especial; 4) desenvolvimento e psicopatologia; 5) atenção, desenvolvimento e psicopatologia, 6) etnicidade, emigração e psicopatologia.

O número 156: 2 do American Journal of Psychiatry (1999) publica artigos dedicados a: terapia (5), imagens de atividade cerebral (3), marcadores das alterações psíquicas (3) metabolismo cerebral (3), nosografia (3), neurotransmissores (2), genética (1), modelo clínico de suicídio (1), religião e medicina (1), custos da saúde mental (1). Pela temática, não seria fácil distinguir esta revista de outras que se intitulam Psicopatologia.

Claro, não estamos referindo aqui os resultados de uma pesquisa; apenas algumas referências que sugerem a diversidade dos temas abarcados nos quadros da Psicopatologia e a variedade dos sentidos atribuídos ao termo. Para qualquer dos sentidos dados a este termo achamos nomes psiquiátricos da maior circulação. 


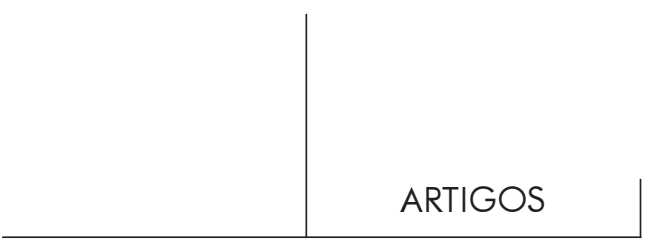

Talvez mais específico seja não o território que os autores atribuem à Psicopatologia. Jaspers a caracterizava pelo método fenomenológico. Outros, contemporâneos e as classificações em vigor, a caracterizam pelo método neurocientífico de abordagem. Talvez nem seja o caso de alguns se alarmarem com o abandono da psicopatologia. As diferenças poderiam consistir em como entendemos fazer Psicopatologia.

Como não temos nenhuma razão de escamotear o conceito de psiquiatria, não há razão para usar Psicopatologia como um substituto. Para separar as noções gerais no estudo das alterações mentais sem entrar na abordagem nosológica, os autores usam ou psiquiatria geral ou psicopatologia, sem explicar a preferência.

Achamos mais adequado falar de psicopatologia quando estudamos o significado das manifestações, a relação entre elas, quando procuramos sistematizálas teoricamente. A semiologia clínica, a nosologia, também comportam teorização, de modo que entre psiquiatria e psicopatologia não fazemos uma separação neste sentido: não postulamos que uma é prática, a outra é teórica. Mas para reflexão sobre a natureza das manifestações de alteração psíquica, sobre as relações entre elas, a explicação delas em função da estrutura psíquica da pessoa doente, sobre a interpretação das manifestações do doente e do instrumental teórico e prático do psiquiatra, o termo psicopatologia nos parece muito adequado.

Segundo Schneider (1961), o psicopatologista descreve o que o paciente comunica. Depois, define termos e lhes atribui sentidos fixados por convenções. Achamos difícil aceitar tal idéia. Recebo as comunicações do paciente expressando suas experiências, já formuladas conforme certas categorias mentais-culturais do mesmo. Por minha vez, conforme minha cultura, meu sistema de pensar, meus pontos de vista, minhas atividades de representação e processamento neural das palavras do paciente, elaboro um discurso sobre ele, aponto sinais de doença, escolho um diagnóstico. Sem dúvida, interpreto, em função do meu sistema de referência. É esta atividade que produz o que chamamos de psicopatologia. É este modo de abordar o paciente, nossa interação com ele, o que produz o discurso, o corpo de saber que chamamos de psicopatologia.

Definir nossas escolhas principais, nossos objetivos e métodos de pensamento e ação, significa para nos definir o que entendemos por psicopatologia, qual é a psicopatologia pela qual optamos.

Usamos o termo Psicopatologia para designar um capítulo do saber sobre os distúrbios mentais, estudando o significado das manifestações, as relações entre elas, formulando os princípios, as teorias que norteiam os procedimentos clínicos, as pesquisas. Entendemos que fazer psicopatologia não se limita a tomar conhecimento do que os psicopatologistas fizeram e fazem neste campo de saber, mas participar, ampliando os conhecimentos, tentando propor soluções para os problemas nãoresolvidos, procurar conceitos, métodos mais satisfatórios. 


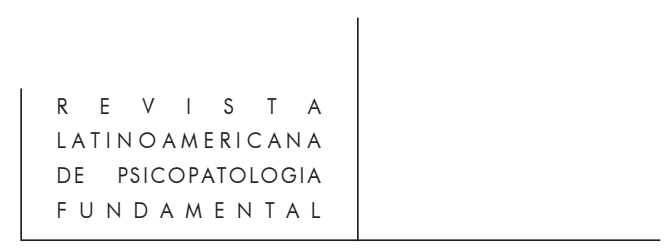

As divergências entre autores, entre resultados de pesquisas, a precariedade das respostas terapêuticas em muitos casos impõem a necessidade de experimentar novos princípios, novos caminhos. Toda a psiquiatria é marcada pela discussão de suas próprias bases. O que deve ser a psicopatologia, como deve ser praticada, é tema presente nos trabalhos dos psiquiatras de todas as orientações.

As questões diárias da clínica nos levaram a formular certos conceitos, quando os propostos pela literatura não nos satisfazem. Para a maioria dos quadros que tratamos, temos certas propostas teóricas, conceituais a fazer.

Tentamos aqui apresentar como exemplo os quadros delirantes sobre os quais nos manifestamos em vários trabalhos (1983, 1985, 1990, 1992, 1996).

Devido às limitações práticas e teóricas da definição do delírio como "crença, convicção, juízo falso incorrigível, incompatível com a cultura do ambiente do indivíduo" aceita, com leves variações, desde Jaspers até os autores destes anos, preferimos diagnosticar delírio nas pessoas que perderam a capacidade de comunicação lógica. O delirante faz afirmações que o examinador não pode aceitar. O delirante, mesmo sabendo que suas declarações não são consideradas verdadeiras, continua fazendo-as.

As pessoas usam a lógica como instrumento para convencer, provar. Não é o que o delirante faz. Encaramos a lógica como instrumento de comunicação. Não é a única forma de pensamento. Existem outros sistemas de explicação, de interpretação, mitológica, religiosa, fantástica, referentes ao mundo, eventos, relações. A lógica não somente não é o único modo de pensar, mas não é nem inata. O pensamento lógico se desenvolve, na criança, depois de muitos anos de vida, de experiências (Piaget, 1969, 1970). Sendo mais nova como função, a prática da lógica é mais exposta a ser comprometida, perdida, em caso de doença.

Condições como fracasso das experiências corporais, podem favorecer o colapso da lógica. As atividades nos levam a identificar certos atos, com a solução de necessidades, satisfação de desejos. O mal-estar constituído pela fome, pode ser eliminado pela ingestão de alimentos. O desejo sexual pode ser satisfeito com a prática de certos atos. As condutas que levam a satisfação, a eliminação de carências, são descobertas pelas experiências vividas. Se um obstáculo perturba a relação entre ação e o resultado desejado, o princípio de identidade elaborado em nossa mente pode ser comprometido. O que fazíamos para obter satisfação, não funciona mais. Ou: o que outros fazem, o que me ensinaram para obter satisfação não funciona para mim. A relação entre fatos, situações, ações não é mais identificável, previsível. Tal perda de identidade pode invadir o campo da comunicação lógica. O que pretendo transmitir, realizar, no contato com o outro, deixa de ser eficaz. A lógica, procedimento difícil de adquirir e de manter, sofre um colapso quando seu uso não é consolidado pelos resultados esperados. O fracasso das experiências corporais pode ser provocado, seja por alterações 


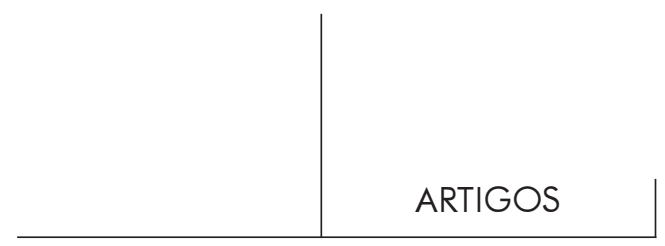

funcionais ou lesionais do sistema nervoso, seja por distúrbios da mobilidade e equilíbrio dos processo neurofisiológicos. Seja, também, por mal uso dos instrumentos, das práticas, com as quais procuramos resolver nossas necessidades. Os conflitos psicológicos, a falta de capacidade de tomar decisões, mantêm o cérebro em constante excitação, sem repouso. O que, sem dúvida, aprofunda o estado de astenia que poderia ser a condição que favorece os conflitos. Observamos que tanto processos físicos quanto psíquicos, podem provocar o colapso da comunicação lógica, cuja expressão pode ser o delírio.

O delirante não consegue mais comunicar-se com o outro. Não consegue adaptar-se às necessidades do interlocutor e fornecer-lhe argumentos aceitáveis. Não consegue explicações para seu fracasso nas relações com os outros, com o mundo. Recorre a explicações que não decorrem das suas experiências anteriores. Seus sofrimentos são atribuídos a perseguições, a inimigos, máquinas, forças sobrenaturais. Sua própria identidade é alterada, já que não consegue atingir, com seus atos, os objetivos que se propõe.

Os delirantes constituem seu mundo não com elementos obtidos pelas suas experiências passadas: adotam as explicações fornecidas pelas crenças comuns, pelas mídias. O conteúdo modifica-se com os momentos da cultura. Ser Deus, ter poderes sobrenaturais, é uma forma de delirar presente nas observações clínicas ao longo do tempo. As figuras que atingem o imaginário mudam, e se no século passado Napoleão era figura clássica nos delírios, atualmente são freqüentemente incluídas no delírio figuras políticas, estrelas de TV, extraterrestres.

É isso que nos permite afirmar que o delirante perde sua subjetividade e sofre um mal comum, com expressões comuns.

Nosso modo de conceber o delírio implica atitudes terapêuticas, hipóteses para pesquisas, reflexões teóricas. Não procuramos localizações cerebrais para identificar o pensamento delirante. Não o explicamos por existência de lesões ou distúrbios funcionais, localizados em uma ou várias regiões. As alterações evidenciadas pelos recursos tecnológicos contemporâneos (Tomografia Computadorizada com emissão de positrons, Ressonância Magnética etc.) são de interesse indiscutível. Mas não podemos concluir que alterações pré-frontais seriam o fator cognitivo, e subcorticais seriam o fator emocional que provocam e modulam o delírio. Nem que as alterações sub-corticais induzem as corticais, ou o contrário. Nem que distúrbios perceptivos constituem a base do delírio.

As explicações dos fenômenos neurobiológicos não podem substituir as interpretações psicopatológicas, nem ser substituídas pelas últimas. O trabalho científico precisa ser desenvolvido em dois níveis diferentes de abordagem, com instrumentos e disciplinas diferentes, com conceitos adequados.

As considerações que fazemos sobre a clínica do delírio nos levam a refletir sobre as essências dos procedimentos científicos. É comum os neurocientistas 




declararem que o dualismo deve ser superado. Mas para explicar a emergência das atividades psíquicas, recorrem ao número extraordinário de neurônios, e das associações neuronais. O que não chega a satisfazer criadores das neurociências como R. Sperry, J.C. Eccles, G. Edelman (para mencionar só prêmios Nobel). Nossa maneira de pensar a atividade psíquica como produto do sistema cérebro-cultura (1995, 1990, 1984, 1982), integram-se com nosso conceito de delírio.

Para diagnosticar, tomamos em consideração o relacionamento do examinado com o examinador. Não procuramos identificar um sintoma, mas o colapso da capacidade de comunicação lógica.

Delírio é um conceito médico usado para nomear certas situações clínicas.

A terapia medicamentosa e psicológica (associadas ou não) visa reestruturar a comunicação com os outros, tornando as atividades neuronais capazes de adaptação.

Apresentamos acima, sumarissimamente, o que entendemos por atividade psicopatológica, com respeito à pessoa com idéias delirantes.

\section{Referências Bibliográficas}

Ahrens, B.; Stieglitz, R.D. (1998). "Psychopathological assessment and diagnosis. A study of single symptoms". Psychopathology, 31(3): 138-152.

ANDREASEN, N.C. "Linking mind and brain in the study of mental illness: a project for a scientific psychopathology". Science, 275: 1586-1592.

ANGelergues, R. (1990). "Qu'est-ce que la psychopathologie. Une question et non une réponse". L'evolution psychiatrique, 55(2): 277-286.

Aragona, M.; Vella G. (1980). "Psychopathological considerations on the relationships between bulimia and obsessive-compulsive disorder". Psychopathology, 31(14): 197-125.

Arieti, S. (1959). American Handbook of Psychiatry. New York, Basic Books. Ed. 11, vol. 2, 2098 págs.

ARnold, W.; EYSENCK, H.J.; Mell, R. (1976). Dicionário de psicologia. São Paulo, Loyola, 1982.

BinswANGER, L. (1922). Sobre fenomenologia. Artículos y conferencias escojidas. Madrid, Gredos, 1973.

Blakinston's New Gould Medical Dictionary (1956). New York, McGraw-Hill.

BROCKINGTON, I.F.; HowARD, R. (1997). "Editorial: a hundred years of psychopathology". Psychopathology (Karger, Basel), 30: 303-308.

Brune, M. (1998). "Ethological remarks on manneirism. Conceptualization and proposal for a definition". Psychopathology, 31(4): 188-196.

Cervera-Enguix; Quintanilla, B. (Espanha) (1993). "Anorexia nervosa: fundamental psychopathological manifestation". In Ріснот, P. \& Rein, W. (eds.). The Clinical Approach to Psychiatry. Collection les empecheurs de penser en rond. Rio de Janeiro, MCG Gráfica, pp. 323-338. 


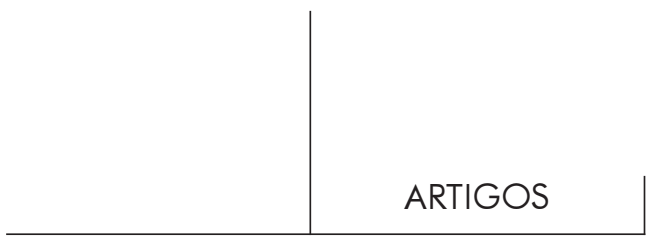

Del Pino, C.C. (1993). “Contribution to psycho(patho)logy and clinical psychiatry”. In Pichot, P.; Rein, W. (eds.). The Clinical Approach to Psychiatry. Op. cit., pp. 171-184.

Deshaies (1967). Psichopathologie générale. Paris. PUF.

Ey, H. (ed.) (1955). Encyclopédie médico-chirurgicale-psychiatrie. Paris, E. H. C., 3 vol.

Ey, H.; Bernard, P.; Brisset, Ch. (1963). Manuel de psychiatrie. Paris, Masson.

FAlRet, J.P. (1864). Des maladies mentales et des asiles d'aliénés. Paris, Baillére.

GabBard, G.O. (1995). Treatments of psychiatric disorders. Second Edition. Washington Amer. Psychiatric Press

Gelder, M. (Oxford) (1993). "Beyond the clinical method: the uses of experimental psychopathology". In Piснот, P.; Rein, W. (eds.). The Clinical Approach to Psychiatry. Op. cit., pp. 185-194.

GrIEsINGER, W. (1845). Traité des maladies mentales. Paris, Delahaye Ed., 1865.

Hinsie, L.E.; Campbell, R.J. (1960). Psychiatric Dictionary. New York, Oxford University Press.

Hu, T.W.; Rush, A.J. (1995). "Depressive disorders". Soc. Psychiatry psychiatr. Epidemiol. 30: 224-230.

Huber. G.; Gross, G. (1993). “Is psychopathology still necessary?”. Psiquiatria biológica 1(1): 61-70.

JASPERS, K. (1913). Psicopatologia geral. Rio de Janeiro, Athaeneu, 1973.

Kandel, E.R.; Schwartz, J.H. (1985). Principles of Neural Science. New York, Elsevier.

KANDEL, R.E. (1999). "Biology and the future of psychoanalysis". Am. J. Psychiatry 156: 505-524.

Kimura, B. (1993). “Aïda (interpersonal) psychopathology”. In Рichot, P.; Rein, W. (eds.). The Clinical Approach to Psychiatry. Op. cit., pp. 115-170.

(1998). "Fenomenologia da depressão estado-limite". Rev Latinoamericana de Psicopatologia Fundamental, 1(3): 11-32.

Kindt, M.; Brosschot, J.F. (1998). "Cognitive avoidance in phobia”. J. Psychopathology and Behavioral Assessment, 20(1): 43-55.

Lebovici, S. (1990). "Plaidoyer pour l'autonomie de la psychopathologie". L'evolution psychiatrique, 55(20): 263-276.

Lewis, A. (1966). “Analysing the analyst”. The Times Literary Supplement, 3346: 317-319.

Marmer, S.S. (1992). "Teorias da mente e psicopatologia”. In TALBOt, J.; Hales, R.; Yudofsky, S. (coord.). Tratado de psiquiatria. Porto Alegre. Artes Médicas., pp. 93-122.

Mayer-Gross, W.; Slater, E.; Roth, M. (1954). Clinical Psychiatry. London, Baillere.

Millon, Th. (1969). Modern Psychopathology. Philadelphia. Saunders.

Minkowski, E. 91966). Traité de psychopathologie. Paris, PUF.

Minsky, M. (1988). La société de l'esprit. Paris, Inter Editions.

Monedero, C. (1973). Psicopatologia general. Madrid, Biblioteca Nueva.

Monti, M.R. (1998). “Whatever happened to delusional perception?". Psychopathology, 31(5): 225-223.

Postel, J. (1980). Dictionnaire de psychiatrie et de psychopathologie clinique. Paris, Larousse. 
SCHNeIDER, K. (1961). Klinische psychopathologie. Stuttgart, Thieme (4a ed.).

ShePherd, M., Zangwill, B.L. (1983). Handbook of Psychiatry. Cambridge, Cambridge University Press, vol. 1.

Sillamy, N. (1980). Dictionnaire encyclopédique de psychologie. Paris, Bordas.

Sonenreich, C.; Bassitt, W.; Estevẽo, G. (1983). "Estruturas delirantes e tratamento". Temas, 24/25: 53-66.

Sonenreich, C.; Correa-Kerr, F.; Estevão, G. (1991). Debates sobre o conceito de doenças afetivas. São Paulo, Manole.

Sonenreich, C.; Friedrich, S. (1990). "Diagnóstico por listagem de sintomas não é nossa escolha". Temas, 38: 41-44.

SonenReich, C.; Friedrich, S.; Ribeiro, P.L. (1992). "Um conceito em debate: esquizofrenia". Temas, 22(44): 171-228.

Talbott, J.; Hales, R.; Yudofsky, S. (1992). Tratado de psiquiatria. Porto Alegre, Artes Médicas.

Thuillier, J. (1996). La folie. Paris, Lafont.

Unnewehr, S.; Schneider, S.; Florin, I.; Margraf, J. (1998). "Psychopathology in children of patients with panic disorder or animal phobia". Psychopathology 31(2): 69-84.

VALLejo-NAGera (1970). Introdução à psiquiatria. Barcelona, Ed. Cientifico-Medica.

\section{Resumo}

El término que Psicopatologia se lo usa en varios sentidos: equivalente la psiquiatría, a la parte de la psiquiatría que trata de las perturbaciones leves en contraposición a las graves, a sintomatologia contrapusta a la nosologia, a las teorías de la psique y dinámica emocional. Los asuntos inclusos bajo este título han sido tratados por otros autores como la Psiquiatría General, la Psicología Médica, la Psiquiatría Clínica. Los autores de los más notables no definen el término propiamente, pero ellos indican cuales deben ser los objetivos, los métodos de trabajo que atribuyen a Psicopatologia. Hemos escogido usar el término para designar los estudios de las teorías del desarrollo, funcionamiento y alteraciones de las actividades mentales, la interpretación de los síntomas y señales com respecto a factores biológicos y psicológicos, el significado de las perturbaciones de la relación y de conducta, las bases principales de los síntomas de la clasificación nosologica. Las investigaciones y reflexiones necesitan ser logradas para actualizar la Psicopatologia. En este sentido, como ejemplo, presentamos ciertas propuestas para conceptuar y trabajar con el delirante.

Palabras llave: Psicopatología, psiquiatría, nosología, síntoma.

Le terme Psychopathologie est employé en differents sens: equivalent de psychiatrie, de la psychiatrie des troubles moins graves, de symptomatologie en 


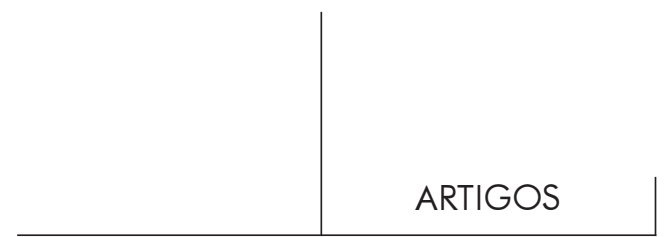

opposition à nosologie, des théories du psychisme et de la dinamique émotionelle. Les thèmes inclus sous ce titre, sont traités par certains auteurs sous des titres comme Psychiatrie Générale, Psychologie Médicale, Psychiatrie Clinique. Certains auteurs, des les plus considérables, ne définissent pas le terme, mais indiquent quels sont les objectifs et les méthodes de travail qu'ils attribuent à la Psychopathologie. Nous choisissons ce terme pour désigner l'étude des théories du développement, functionnement et altération des activités mentales, l'interpretation des symptomes et signes en function des facteurs biologiques et psychologiques, la signification des troubles du relationement et comportement, les principales bases des classification nosologiques. Des recherches et reflexions sont nécessaires pour actualiser la Psychopathologie. Dans ce sens, nous présentons comme exemple, quelques propositions aptes à concevoir et travailler avec les délirants.

Mots clés: Psychopathologie, Psychiatrie, nosologie, symptome.

The term Psychopathology is used in various senses: equivalent of Psychiatry, the part of psychiatry which deals with mild disorders as opposed to severe ones, to symptomatology as opposed to nosology, theories of psychism and emotional dynamics. The topics included in the title are adressed by other authors as General Psychiatry, Medical Psychology, Clinical Psychiatry. Even the most renown authors do not properly define the term, but indicate what objectives and work methods should be attributed to Psychopathology. We have chosen to use the term to designate the study of the theories about development, functioning and changes in mental activities, the interpretation of the symptoms and signs in terms of biological and psychological factors, the meaning of relationship and conduct disorders, the major bases of nosologic classification symptoms. Researches studies and reflections are required to update Psychopathology. In this sense, for example, we have presented certain ideas to conceptualize it and work with delirious patients.

Key words: Psychopathology, psychiatry, nosology, symptom. 